\title{
Experimental and numerical analysis of normal and oblique ballistic impacts on thin carbon/epoxy woven laminates
}

\author{
J. López-Puente *, R. Zaera, C. Navarro \\ Carlos III University of Madrid, Department of Continuum Mechanics and Structural Analysis, Avda. de la Universidad 30, 28911 Leganés, \\ Madrid, Spain
}

\begin{abstract}
A finite element numerical model for carbon/epoxy woven laminates has been used to predict residual velocity and damaged area when subjected to high impact velocities. Experiments using a gas gun were conducted to investigate the impact process and to validate the model, measuring the two variables previously indicated. A morphology analysis was also made to investigate the different breakage mechanisms that appear during the penetration process. The influence of the impact velocity and obliquity has been studied using the numerical tool, in a wide range of impact velocities and considering two impact angles, $0^{\circ}$ and $45^{\circ}$.
\end{abstract}

Keywords: A. Carbon fiber; B. Impact behaviour; C. Computational modelling

\section{Introduction}

Aircraft structures may be subjected to a variety of environmental impact hazards. Radome, radar antenna, canopy, windshield, lateral section or intake of the engine nacelle, propeller blades, wing or tail empennage leading edges, fuel tank inside wings are eventually targets of high-velocity impact loading during flight, takeoff, and landing. There are a number of different causes for these shocks: bird strikes [1] and hailstones [2] being the most critical because of their high probability of occurrence. However, the ice released from the edge of the blade of a propeller may also impact the nacelle of the twin engine or the fuselage, and a tyre fragment may impact the underside of wing structures [3]. The accident of the Concorde in 2000 was actually caused by a tyre fragment impacting a fuel tank on the wing of the airplane. Damage on structural elements due to impact may also occur if the blade of an aeroengine turbine fails due to fatigue and penetrates the wall of the containment cell, penetrating oil tanks and air-

\footnotetext{
* Corresponding author. Tel.: +34 916248881; fax: +34 91629973.

E mail address: jlpuente@ing.uc3m.es (J. López Puente).
}

frames [4]. Other kinds of projectiles that may impact combat aircraft structures are small and medium calibre bullets or fragments due to grenade explosions.

Impact engineering is also critical in the field of spacecraft. The near-earth space environment, where satellites, the International Space Station, and the Space Shuttle orbit the earth, is jumbled with both artificial and natural debris $[5,6]$. These are too small and numerous to be individually tracked and there are many satellites in orbit, so that probability of destructive collision is non-negligible. Moreover, airspace structures may be impacted not only during orbit but also during re-entry phases. A catastrophic example was the impact of frozen piece of insulating foam on the wing of the Columbia Space Shuttle [7].

The risk of damage due to impacts is nowadays well recognised in aircraft and spacecraft design. Carbon fibre reinforced composites are used extensively in both industries. These materials are used increasing in many military and civil applications due to their excellent mechanical properties: high specific strength, specific stiffness, resistance to corrosion, increased fatigue life, etc. However, a major concern in the use of CFRPs is their poor translaminar properties, which become critical under impact 
loading. The structural components may undergo extensive damage when subject to impact loads, with the corresponding decrease of their residual strength and the subsequent risk of structural failure under service. And this has motivated several experimental studies in this field (Table 1). Cantwell and Morton [8] performed high velocity impact tests to examine the initiation and development of damage. Geometrical parameters such as the width and length of the target appear to have very little effect on the impact response. Ballistic impact tends to produce greater levels of damage and therefore larger reductions in residual tensile strength. Bland and Dear [9] presented a broad set of experimental results of projectiles impacting carbon fibre reinforced polymers, and a qualitative analysis of the different types of failure resulting from these regimes. Caprino et al. [10] performed ballistic tests on stitched CFRP panels of different thicknesses and used the results to verify the analytical models previously proposed by Reid and Wen [11] and by Cantwell and Morton [8,12]. Both models proved to be reliable to predict the perforation energy as a function of target thickness, whereas only the model of Cantwell and Morton [8,12] (modified by Caprino et al. [10]) was effective in modelling the influence of the bullet diameter. This work also analyses the different damage modes in the composite for different laminate thicknesses, impact energies, and impact velocities. Sun and Potti [13] performed quasi-static punch experiments and dynamic penetration test on CFRPs. The punch curve obtained from the former was used as "structural constitutive model" that captures the highly non-linear behaviour of the laminate during the penetration process. This pattern curve was user to feed a model developed by the workers to predict both the ballistic limit and the residual velocity in case of perforation. Hammond et al. [14] studied highvelocity fibre impact on carbon fibre-reinforced polymers

Table 1

List of experimental works including impacts on CFRPs at velocities within the range $70530 \mathrm{~m} / \mathrm{s}$

\begin{tabular}{|c|c|c|c|c|c|}
\hline Authors & Year & $\begin{array}{l}\text { Projectile } \\
\text { material }\end{array}$ & $\begin{array}{l}\text { Mass } \\
\text { range } \\
(\mathrm{g})\end{array}$ & $\begin{array}{l}\text { Velocity } \\
\text { range } \\
(\mathrm{m} / \mathrm{s})\end{array}$ & $\begin{array}{l}\text { Obliquity } \\
\left({ }^{\circ}\right)\end{array}$ \\
\hline Bland and Dear [9] & 2001 & Steel & 1 & 100250 & 0 \\
\hline $\begin{array}{l}\text { Cantwell and } \\
\text { Morton [8] }\end{array}$ & 1989 & Steel & 1 & 1070 & 0 \\
\hline Sun and Potti [13] & 1997 & Steel & 1230 & 60200 & 0 \\
\hline Larsson [17] & 1997 & Steel & 0.88 & 210380 & 0 \\
\hline Will et al. [20] & 2002 & Steel & 10.1 & 34139 & 0 \\
\hline Tanabe et al. [18] & 2003 & Steel & 0.5 & 150314 & 0 \\
\hline Tanabe et al. [19] & 2003 & Steel & 0.5 & 1501300 & 0 \\
\hline $\begin{array}{l}\text { López Puente } \\
\quad \text { et al. [30] }\end{array}$ & 2003 & Steel & 1.7 & 60525 & 0 \\
\hline $\begin{array}{l}\text { Hammond } \\
\text { et al. }[14]\end{array}$ & 2004 & Steel & 8.4 & 460 & 0 \\
\hline Hosur et al. [16] & 2004 & Steel & 14 & 46275 & 0 \\
\hline $\begin{array}{l}\text { Herzsberg and } \\
\text { Weller }[15]\end{array}$ & 2006 & Steel & 8.9 & 3990 & 0 \\
\hline Caprino et al. [10] & 2006 & Steel & 8.432 .8 & $65 \quad 129$ & 0 \\
\hline Kim et al. [22] & 2003 & Ice & 862 & 30200 & 0 \\
\hline
\end{tabular}

and performed an extensive work to measure in-plane and out-of-plane deformation of the sample during impact, the residual velocity of the projectile, as well as microscopic and macroscopic damage. Herzsberg and Weller [15] fired steel spherical projectiles at postbuckled carbon/epoxy laminates, stitched and unstitched, to study an eventual catastrophic failure due to impact damage. Hosur et al. [16] carried out high-velocity impact tests up to perforation on stitched and unstitched panels. The damage was less in the stitched samples than in the unstitched samples. However, the presence of stitches lowered the ballistic limit. Larsson [17] performed also ballistic tests on stitched and unstitched carbon fibre laminates, concluding that damage was reduced in the sewed panels. Tanabe et al. $[18,19]$ analysed the behaviour of carbon-reinforced plastics damaged by the impact of a steel sphere. The stress and stress-time histories on the specimens were strongly affected by the type of carbon fibre used and by the fibre/matrix interface strength. The effect of stacking sequence on the ability of the laminate to dissipate the kinetic energy of the projectile was studied by Will et al. [20]. And the differences in the response of CFRP laminate manufactured with woven or tape plies were discussed in the work due to López-Puente et al. [21], showing that tape laminates are less effective against impact than woven laminates, both below and above the ballistic limit, due to the different flexural behaviour of its plies. This work also shows the strong effect of temperature (within the range $-150{ }^{\circ} \mathrm{C}$ to $25^{\circ} \mathrm{C}$ ) on the damage extension produced by the impact on the laminate due to in-plane thermal stresses. Using spherical-shaped ice to simulate hailstones, Kim et al. [22] pelted woven carbon/ epoxy panels to determine the damage resistance of thinwalled composite structures to ice impact. Experiments showed a linear relationship between the kinetic energy at which failure begins and the thickness of the panel. All these works, which are summarized in Table 1, provide valuable information for developing simulation tools.

Abrate published several reviews $[23,24]$ on ballistic impact of laminated composite materials. The improvement in the development of analytical $[8,12,11,25]$ or numerical [26,27] models requires experimental results. Qualitative observation reveals the keys of the structural response of the composite laminate, leading to the hypothesis of the model; quantitative measurements enables the validation of the models developed, to ensure reliable results. Most of the results are relative to impacts performed at normal incidence. Just a few of them were done at a certain obliquity and only at hypervelocity [28,29], far away from the high-speed range which is valuable for aircraft applications.

In this work, the influence of the obliquity of high velocity impacts on the response of woven CFRP thin laminates is investigated. It consists of an experimental part in which impact tests have been completed in a wide range of velocities from values characteristic of an airplane landing or taking off $(70 \mathrm{~m} / \mathrm{s})$ to values in the ballistic range $(500$ $\mathrm{m} / \mathrm{s}$ ), at two impact angles $0^{\circ}$ and $45^{\circ}$. The results helped 
determine ballistic limit velocities, residual velocities, and the morphology as well as the extent of damage to the laminates. They have likewise validated a finite-element model in which a damage model specifically for woven CFRP has been implemented. The numerical model has been used at a later time to extend the analysis to other impact obliquities.

\section{Experimental procedure}

The first step of this work was the selection of the material. Carbon fibre epoxy laminates could be manufactured using different types of fibres and matrices. AS-4 fibre with 8552 epoxy matrix, a well-known combination, was chosen for this work (manufactured by Hexcel composites). Among the different architectures we selected woven, since it is one of the most widely used materials in the aeronautic and aerospace industries for structures subjected to bending or torsion forces. Moreover, this reinforcing architecture offers greater suitability when using recent low-cost manufacturing techniques [16]. The specimens were composed by 10 plies with the same fiber orientation in all of them, with a total thickness of $2.2 \mathrm{~mm}$, and its area was $80 \times 80 \mathrm{~mm}^{2}$.

The projectile used to strike the laminate was a tempered steel sphere with a $7.5 \mathrm{~mm}$ diameter and $1.73 \mathrm{~g}$ mass. This shape avoids the presence of mistaken impacts by the change of yaw angle during the projectile flight; the use of such a hard material, allows a better understanding of the mechanisms of energy absorption by damage in the laminate, since a sphere does not deform plastically, but only decreases the initial energy by slowing its velocity. The same conclusion was reached by Bland and Dear [9] with a similar high-velocity projectile impact against carbon fibre reinforcing polymers.

For the test, a light-gas gun was used. This experimental device uses helium at 300 bar pressure to impel the projectile up to velocities of $550 \mathrm{~m} / \mathrm{s}$, through a $7.62 \mathrm{~mm}$ calibre barrel. Two optical barriers detect the sphere pass, and send signals to the computer that calculates the impact velocity. At the end of the 2-m-long gallery, a $1 \times 1 \times 1 \mathrm{~m}^{3}$ impact chamber is located, where the composite specimen is simply supported along its edges by aluminium guides. Under high-velocity impact conditions the same damage was observed in the laminate, irrespective of the clamping device, as was also observed by Bland and Dear [9].

To measure the residual velocity, a high-speed digital camera (FlashCam PCO) was placed beside the impact chamber, and a $500 \mathrm{~W}$ halogen light was placed inside the chamber. The camera could take up to 10 superposed images with a very short exposure time; a value of $1 \mu \mathrm{s}$ was chosen to obtain a sharp picture. To trigger the camera, two sheets of aluminium, separated by a sheet of paper and connected to an electronic circuit, were attached to the front of the specimen; the sheets were short-circuited by the steel sphere, giving a signal to the camera. The residual velocity was calculated by dividing the distance between spheres by the time interval between superposed images. The rule that appears at the bottom of the picture served to scale the pixel size.

Once the specimen was impacted, the extent of the internal damage induced by the projectile was measured using the C-Scan non-destructive inspection method. Fig. 1a shows an image of a tested laminate obtained with this NDT.

Finally the specimens were carefully cut with a diamond yarn cutter along a transverse plane containing the projectile path (Fig. 1b). Images of this section were captured with an optical microscope, allowing the analysis of the different break- age mechanisms. These pictures also make it possible to correlate the attenuation level of the C-Scan images to real damage. This threshold is key to reliable measurement of the extent of the damage.

\section{Experimental results}

After a set of impact tests at velocities between 70 and $531 \mathrm{~m} / \mathrm{s}$, the ballistic limit $v_{\mathrm{bl}}$ (which is the minimum impact velocity needed for penetration) was found to be around $100 \mathrm{~m} / \mathrm{s}$ for normal impact and around $150 \mathrm{~m} / \mathrm{s}$ for impacts at $45^{\circ}$ obliquity. More than 20 test have been made for each impact angle in order to cover adequately the whole range of impact velocities. Due to the different a

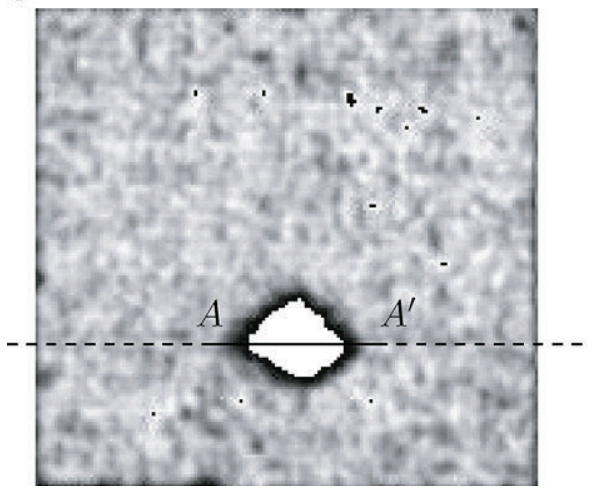

b

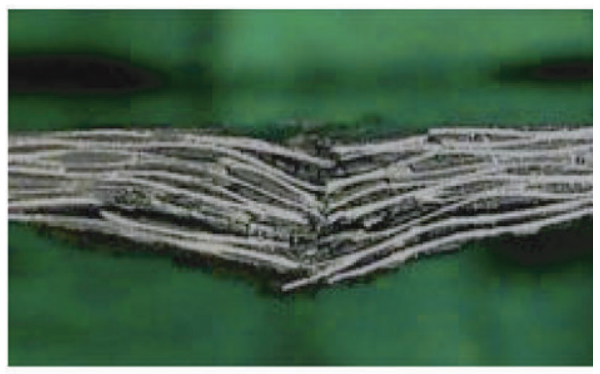

Fig. 1. C scan figure (a), and its corresponding cut image (b); normal impact at $91 \mathrm{~m} / \mathrm{s}$. 
behaviour of the laminate observed below and above ballistic limit, the analysis of the damage is going to be investigated separately for velocities below and above ballistic limit.

\subsection{Impacts below ballistic limit}

Breakage in these kinds of laminated materials is highly localized around the impact point, and the damage extent is always smaller than twice the projectile diameter. Even below the ballistic limit, the impact velocities considered were high enough for a strongly transient response, as opposed to quasi-static conditions, with little global structural response $[9,10]$. Figs. $2 \mathrm{a}$ and $\mathrm{b}$ show the cross-section of two laminates tested below $v_{\mathrm{bl}}$. The specimen submitted to normal impact shows a crushed zone in the impacted face and fibre tensile failure of the fibre in the bottom plies; a conical-shaped shear plug started to form. In addition, small interlaminar cracks were found, progressively longer as they approached the back surface of the laminate. The specimen submitted to oblique impact showed little delamination in the last ply. This damage was presumably due to a spalling effect, since delamination is dominated by through-thickness stress waves for high-velocity impacts [9]. Both laminates were impacted at the same velocity $\left(v_{i} \quad 92 \mathrm{~m} / \mathrm{s}\right.$ ) but the damage extent was notably larger for normal incidence as a result of the higher out-of-plane component of the projectile-target contact force. This was also observed in all the specimens tested below $v_{\mathrm{bl}}$.
The complete set of cross-section images indicates that damage extent increases with the initial projectile velocity $v_{i}$ both for normal and oblique impacts. In addition, the maximum damage inflicted, corresponding to the ballistic limit, was greater for the normal impact; this can be explained by analysing the images of the laminate bottom face. The normal impact produces a rhomboidal breakage shape, with two symmetrical axes and four different aperture planes; oblique impact produces a rectangular breakage scheme, where the characteristic damage length is smaller. Fig. 3 shows the different breakage scheme and explains why perpendicular impact produces a larger damage area.

After the specimens were inspected by C-Scan and the damage extensions were measured using image-processing software, the results were plotted versus impact velocity in Fig. 4. These quantitative results confirm the above observations: the damage extent increases with impact velocity. When $v_{i}$ is not high enough to perforate the laminate, the kinetic energy of the projectile is absorbed by the laminate only through damage, with no transfer of linear momentum. Assuming a linear relation between delaminated area $A_{\mathrm{d}}$ and absorbed energy, which was confirmed by Caprino et al. [10] for ballistic impacts on thin CFRP laminates, $A_{\mathrm{d}}$ should then increase proportionally to the kinetic energy of the projectile, or to the square of the projectile's velocity. Two regression curves in Fig. 4 with a fairly high regression coefficient, one for each set of points, confirm this hypothesis. The curves were calculated just

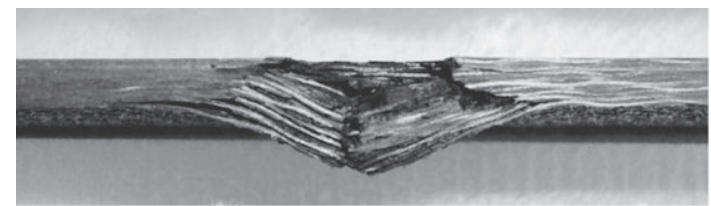

(a) $92 \mathrm{~m} / \mathrm{s}, 0^{\circ}$

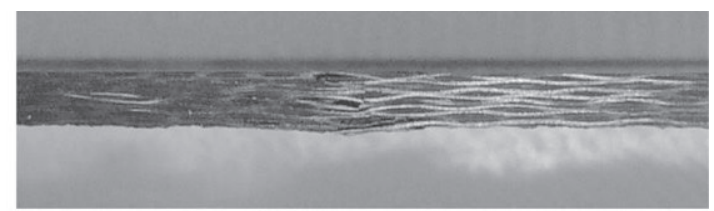

(b) $92 \mathrm{~m} / \mathrm{s}, 45^{\circ}$

Fig. 2. Images of cross section of woven laminates impacted below the ballistic limit.

a

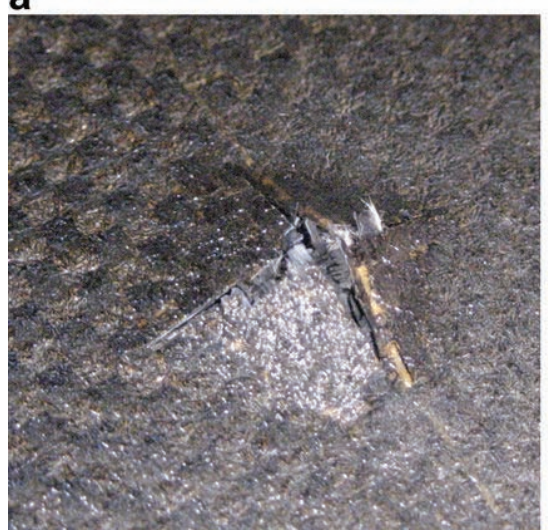

b

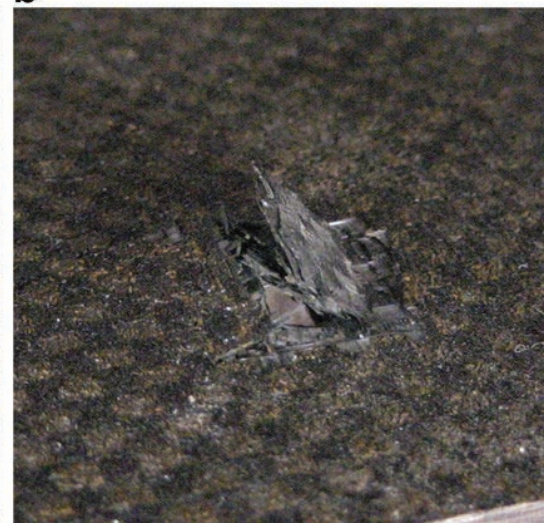

Fig. 3. Bottom view images of woven laminates impacted at close to the ballistic limit, at different angles: (a) $0^{\circ}$ and (b) $45^{\circ}$. 


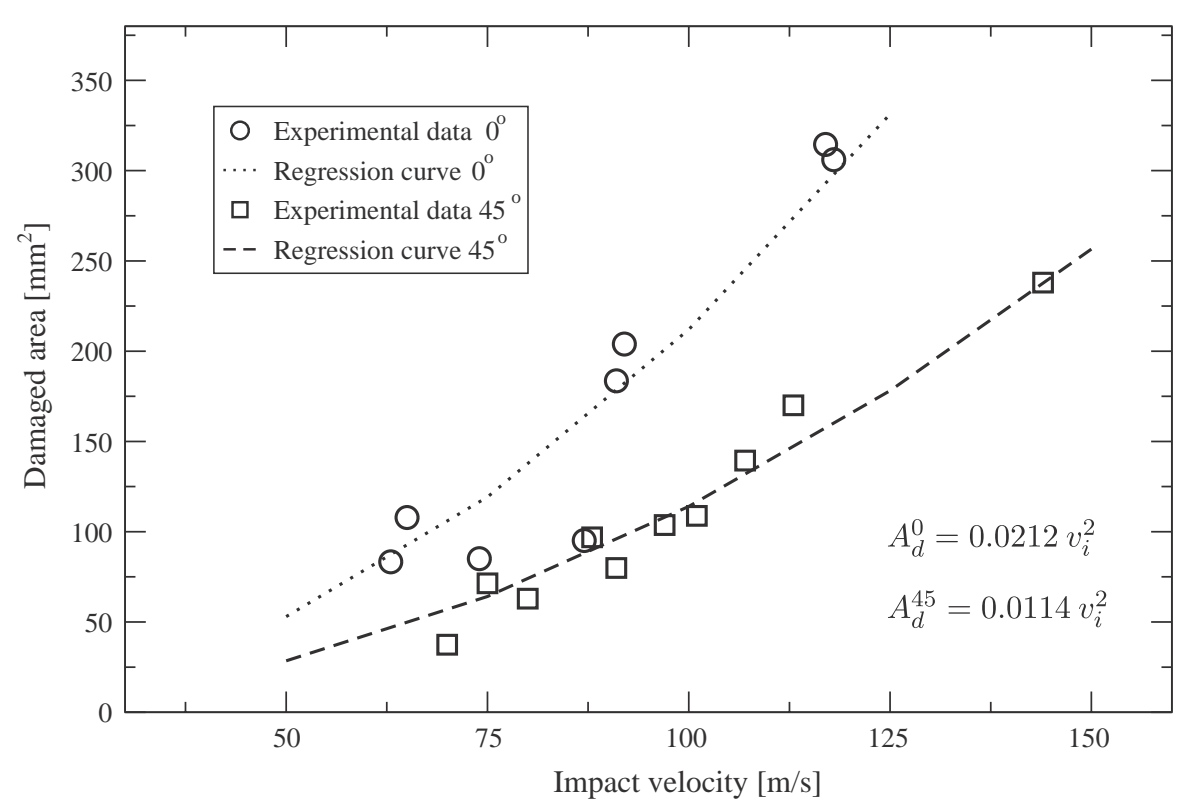

Fig. 4. Regression curves for experimental results; low velocity impacts.

with a quadratic term $A_{\mathrm{d}}=K v_{i}^{2}$, which also forces the damage extent to be zero for no impact velocity (avoiding the effect of threshold damage energy which should correspond to a low value of the impact velocity).

Fig. 4 (or Fig. 5) also confirms the visual observations of the cross-sections: the damage extent for normal impacts is larger than that for the oblique impacts. Below $v_{\mathrm{bl}}$, the projectile barely penetrates the laminate; thus the component of the projectile velocity parallel to the laminate almost no induces damage: the stiffness and strength in the inplane direction is very high compared to the one through-thickness direction. Assuming that the normal component of the velocity is the one that induces damage on the laminate, it is possible to establish an approximate relationship between the damage extent produced by an oblique impact $A_{\mathrm{d}}^{\alpha}$ and a normal one $A_{\mathrm{d}}^{o}$

$A_{\mathrm{d}}^{\alpha} / A_{\mathrm{d}}^{0} \approx \cos ^{2} \alpha$ $\alpha$ being the impact angle. In the present case $A_{\mathrm{d}}^{45} / A_{\mathrm{d}}^{0} \approx$ $\cos ^{2} 45^{\circ}=0.5$. A value close to 0.5 could be also obtained by dividing the quadratic expressions given by the regression curves in Fig. 4

$\frac{A_{\mathrm{d}}^{45}}{A_{\mathrm{d}}^{0}}=\frac{0.0114 v_{i}^{2}}{0.0212 v_{i}^{2}}=0.54$ for $v_{i}<v_{\mathrm{bl}}$

This result supports the hypothesis of major influence of normal velocity of the projectile in the damaged area.

\subsection{Impacts above ballistic limit}

Above ballistic limit the damage extension decreases with velocity. The decrement it not easy to observe in the cross-sections, depicted in Figs. 6a and c (normal impact), $6 \mathrm{~b}$ and $6 \mathrm{~d}$ (oblique impact). Nevertheless in those images it is possible to distinguish a conical-shaped shear-plug failure, slightly oriented to the impact direction in the oblique a

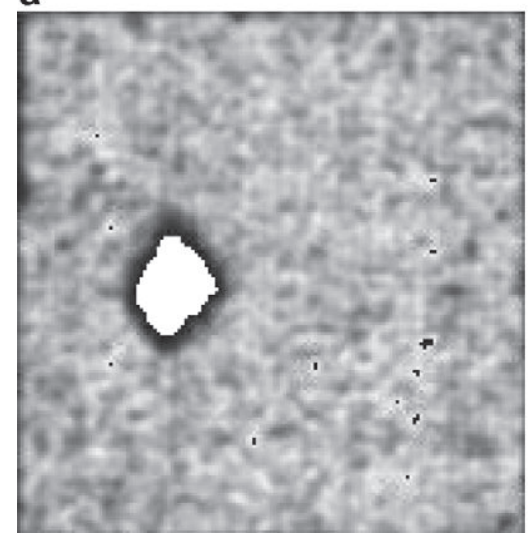

b

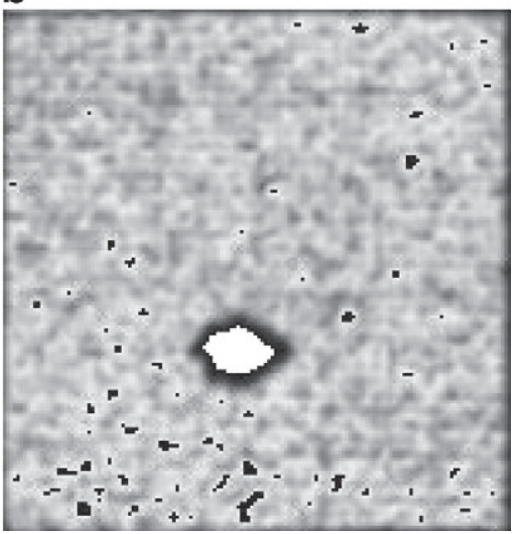

Fig. 5. Ultrasonic C Scan images of woven laminates impacted at $92 \mathrm{~m} / \mathrm{s}$, with different angles: (a) $0^{\circ}$ and (b) $45^{\circ}$. 


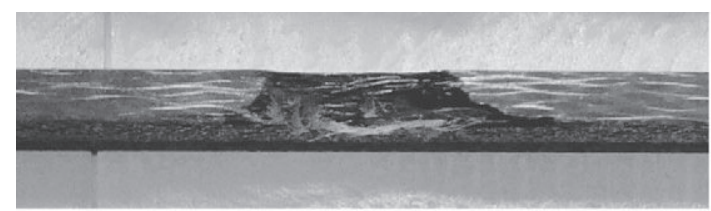

(a) $196 \mathrm{~m} / \mathrm{s}, 0^{\circ}$

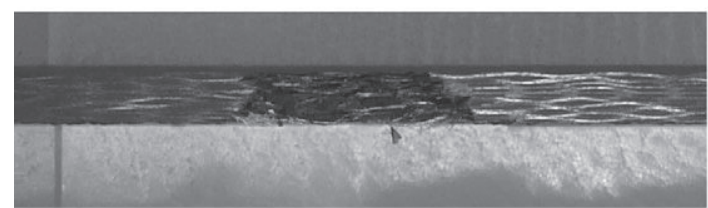

(c) $354 \mathrm{~m} / \mathrm{s}, 0^{\circ}$

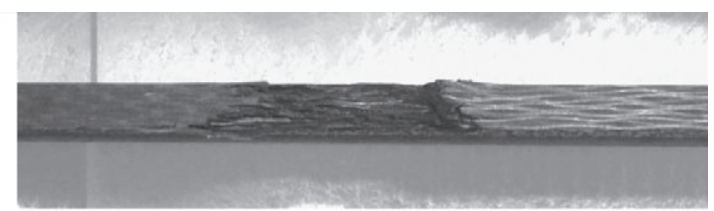

(b) $191 \mathrm{~m} / \mathrm{s}, 45^{\circ}$

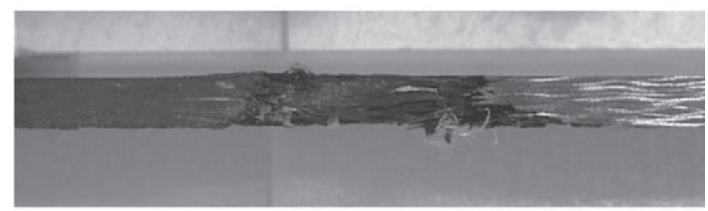

(d) $362 \mathrm{~m} / \mathrm{s}, 45^{\circ}$

Fig. 6. Images of cross section of woven laminates impacted above ballistic limit.

cases. This conical hole changes to a cylindrical shape parallel to the projectile trajectory as impact velocity increases; in addition some interlaminar cracks appear close to the crater but their area is much smaller than that observed in specimens impacted at velocities below $v_{\mathrm{bl}}$.

The damage area measurements with the C-Scan also support these trends (Fig. 7). The damage extent decreases with velocity both for normal and oblique impacts. At high velocities the main mechanism developed by the laminate to absorb the energy of the projectile is the momentum transfer [25] and scant delamination is observed. As $v_{i}$ decreases the penetration process takes more time and local bending phenomena and thus delamination-start to play a role. As observed in the images of the cross sections (Fig. 6), the hole produced by a high-velocity impact has the shape of the intersection between the laminate and the trajectory of the projectile, and damage is strongly localized around this orifice. Thus, the projection of the damaged area corresponding to very-high impact velocities should be close to an ellipse with semi-axes $a \quad r$ and $b \quad r /$ $\cos \alpha+h / 2 \tan \alpha$, plus the surrounding delaminated zone, $r$ being the projectile radius and $h$ the laminate thickness. Fig. 8 shows this shapes for normal and oblique impacts at velocities around $475 \mathrm{~m} / \mathrm{s}$. The black regions represent the hole, and the white regions correspond to the delaminated material. Fig. 9 shows C-Scan images of laminates impacted at a lower velocity, around $250 \mathrm{~m} / \mathrm{s}$ : the delaminated region around the orifice has a larger extent and the projection of the whole damaged area separates from the elliptical shape for oblique impacts. Fig. 7 also confirms visual observations of the cross-sections: the damage extent for normal impacts is lower than that for the oblique impacts.

We can fit the experimental points depicted in Fig. 7 with a regression curve, assuming that the damaged area decreases with the impact velocity. Let us define $\delta_{\mathrm{d}}$ which

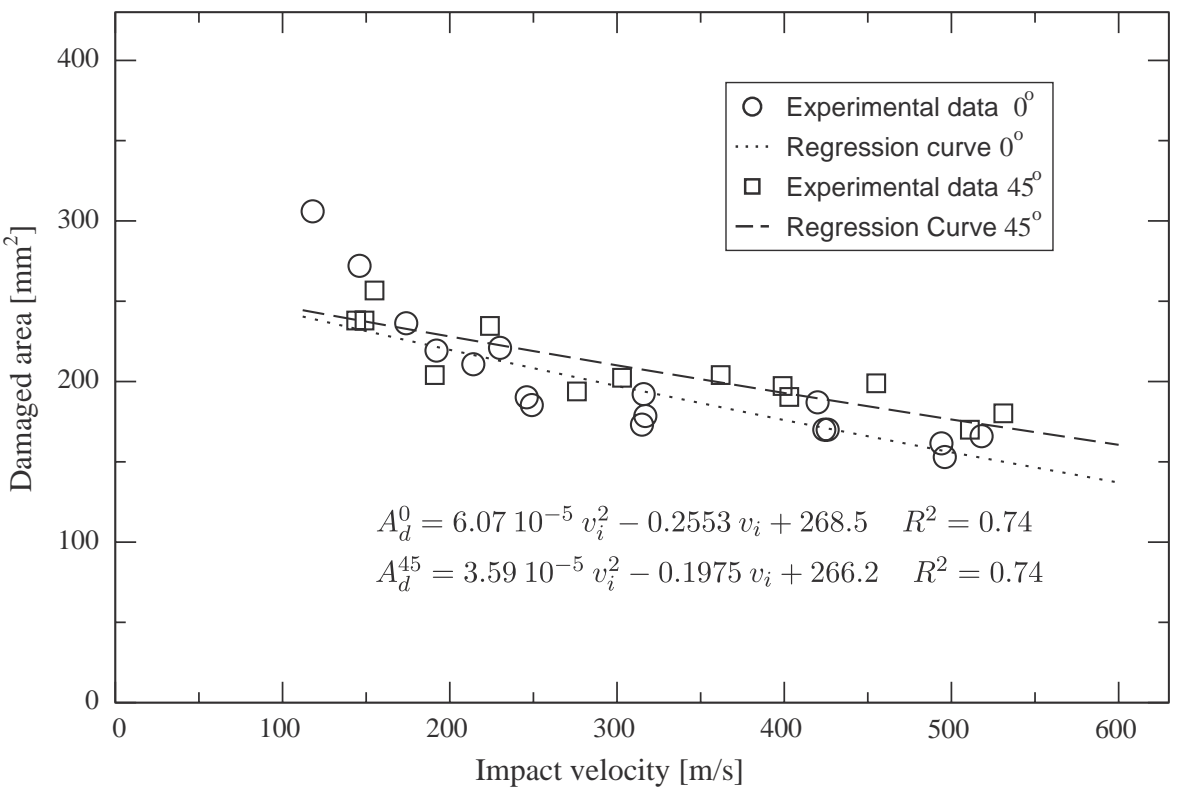

Fig. 7. Regression curves for experimental results; high velocity impacts. 
a

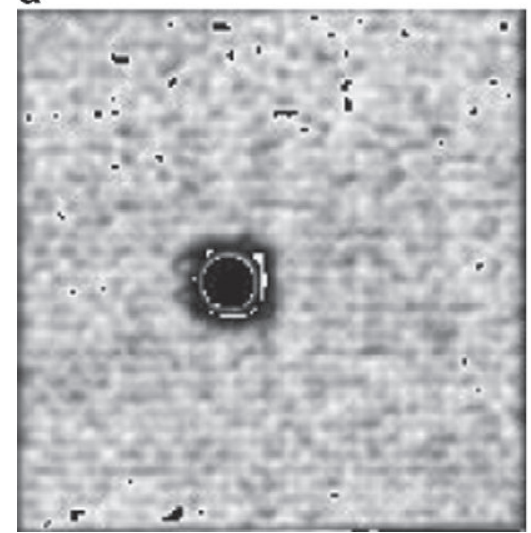

b

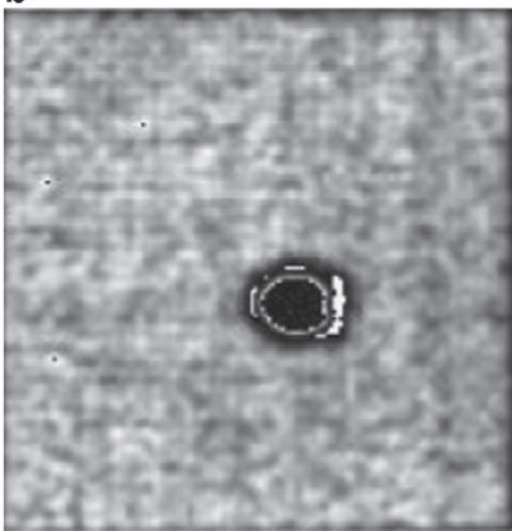

Fig. 8. Ultrasonic C Scan images of woven laminates impacted around $475 \mathrm{~m} / \mathrm{s}$, with different angles; (a) $0^{\circ}$ and (b) $45^{\circ}$.

a

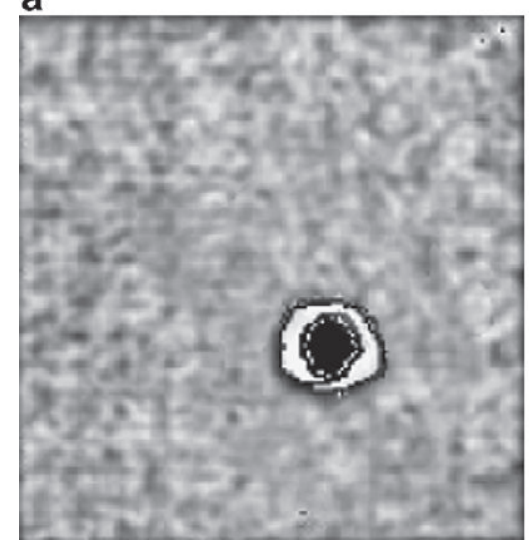

b

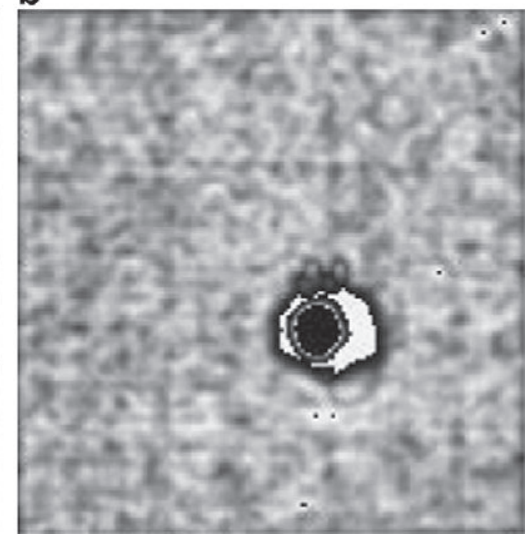

Fig. 9. Ultrasonic C Scan images of woven laminates impacted around $250 \mathrm{~m} / \mathrm{s}$, with different angles; (a) $0^{\circ}$ and (b) $45^{\circ}$.

represents the thickness of damage surrounding the orifice after a high-velocity impact. The damaged area could then be calculated then using the equation

$$
\begin{aligned}
A_{\mathrm{d}}^{l i m} & \approx \pi\left(a+\delta_{\mathrm{d}}\right)\left(b+\delta_{\mathrm{d}}\right) \\
& \approx \pi\left(r+\delta_{\mathrm{d}}\right)\left(\frac{r}{\cos \alpha}+\frac{h \tan \alpha}{2}+\delta_{\mathrm{d}}\right)
\end{aligned}
$$

This surrounding damage must be defined taken into account that it should decrease with impact velocity, and that a limit velocity it should exist at which $\delta_{\mathrm{d}}$ must be zero. The time needed for the elastic shock waves to travel through the thickness is $t^{*} \quad 2 h / c_{3}$ (where $c_{3}$ is the trough-thickness speed of sound); on the other hand, the time needed for the projectile to perforate the laminate at high velocities is approximately $t_{\mathrm{p}} h / v_{i}$. It could be assumed that when $v_{i}>c_{3} / 2$ the surrounding damage is zero, because the laminate does not have enough time to respond against the impact (López-Puente et al. [25]). The proposed trend becomes

$\delta_{\mathrm{d}}=k_{\alpha}\left(\frac{c_{3}}{2}-v_{i}\right)$ where $k_{\alpha}$ is a variable that depends on the impact angle. Then, substituting Eq. (4) in to Eq. (3), it is possible to obtain an expression that represents the damaged area as function of the impact velocity, in which the constant $k_{\alpha}$ could be estimated by a regression analysis, using the experimental data for high-velocity impacts. Fig. 7 shows the regression curves and the equations with its regressions coefficient.

The parameter $k_{\alpha}$ in the Eq. (4), takes into account the damage extent around the projectile impact. Its value, calculated from the regression analysis, diminishes with the impact angle, which it is the expected behaviour. As soon as the impact angle increases, part of the surrounding damaged zone (located mainly at the bottom face of the laminate) is hidden during C-Scan inspection by the entry plug-in zone (located at the top face of the laminate); Fig. 10 shows a sketch of this phenomenon, observed during the cross-section inspection of the laminate.

At impact velocities close to the ballistic limit $v_{\mathrm{b} 1}$ the curves corresponding to normal and oblique impact will intersect as a result of the change in the trends. When $v_{i}<v_{\mathrm{bl}}$ the energy of the projectile is absorbed mainly by 


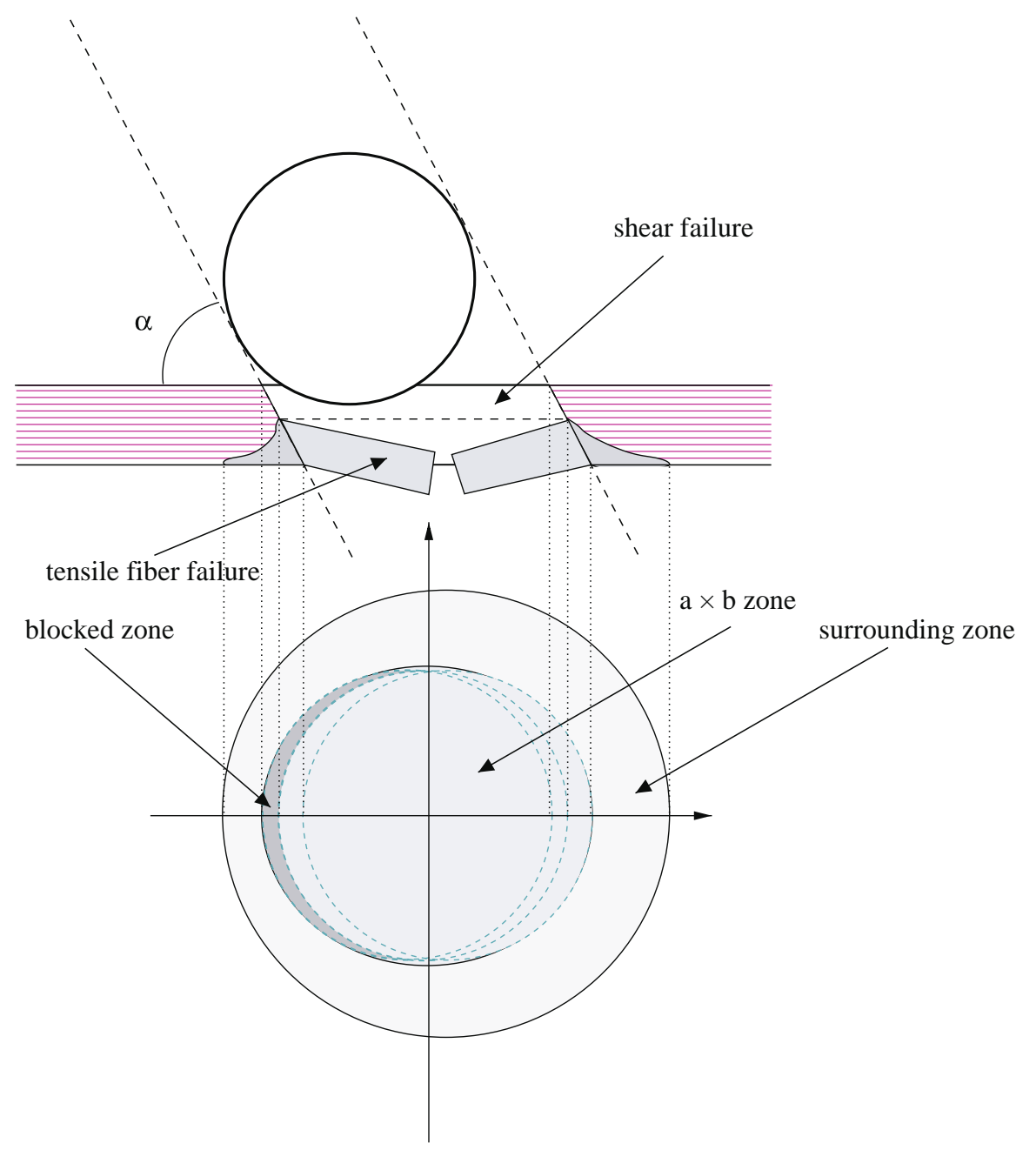

Fig. 10. Sketch of the penetration process and the damaged area induced.

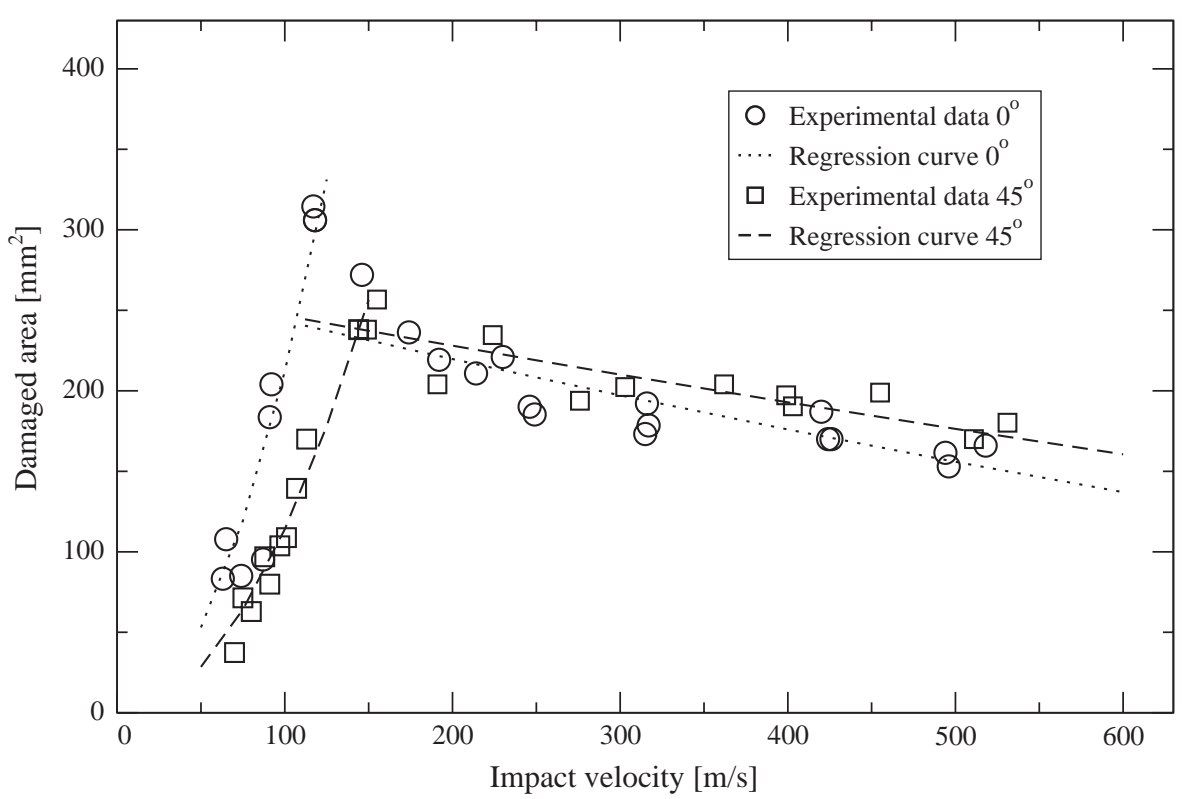

Fig. 11. Damaged area vs impact velocity for different impact angles. Experimental results. 
damage in the laminate and its extension is larger for normal impacts; when $v_{i}>v_{\mathrm{bl}}$ the energy is absorbed mainly by the momentum transfer from the projectile to the laminate plug, and the damage extent measured with C-Scan is larger for oblique impacts. Fig. 11 shows the set of experimental values for the whole range of impact velocities.

\section{Description of the numerical model}

For the numerical simulations, the finite element commercial code ABAQUS/Explicit [31] was used.

\subsection{Material modelling}

Two different solids participate in the impact process, projectile and laminate. Because no plastic deformation has been found in the sphere after the impact tests, a linear elastic behaviour was chosen for the steel of the projectile (E $210 \mathrm{GPa}, v \quad 0.3$ and $\rho \quad 7800 \mathrm{~kg} / \mathrm{m}^{3}$ ). The material model used for the carbon/epoxy woven laminate derives from the Chang Chang model [32], which has been used widely in the literature $[30,33,34]$. This model considers four different types of damage and defines different damage variables $d$ (stress dependent) that vary from 0 (no damage) to 1 (fully broken). When $d$ equals one, the material looses its strength and hence some of the stress components are set to zero.

Some modifications were made in this model since it was developed for tape plies and not for woven ones; some of these modifications have been presented in a previous work [30]. Only two of the four failure criteria were used here:

- Delamination: The damage variable follows the equation:

$$
d_{\mathrm{d}}=\left(\frac{\sigma_{33}}{Z_{\mathrm{r}}}\right)^{2}+\left(\frac{\sigma_{23}}{S_{23}}\right)^{2}+\left(\frac{\sigma_{13}}{S_{13}}\right)^{2}
$$

This criteria applies only to out-of-plane tension $\left(\sigma_{33}>0\right) . Z_{\mathrm{r}}$ represents the interlaminar strength, and $S_{23}$ y $S_{13}$ corresponds to the shear strength in the 23 and 13 directions, respectively. When $d_{\mathrm{d}} \quad 1$ the stresses components that appear in the equation are set to zero.

- Fiber failure: This damage criteria, which considers tensile and compressive fiber breakage, was slightly modified: fibers exist in two directions (1 and 2). Hence two different equations are used, Eq. (6) for fibers at $0^{\circ}$, and Eq. (7) for fibers at $90^{\circ}$ :

$$
\begin{aligned}
& d_{\mathrm{f} 1}=\left(\frac{\sigma_{11}}{X_{\mathrm{T}}}\right)^{2}+\left(\frac{\sigma_{12}^{2}+\sigma_{13}^{2}}{S_{f}^{2}}\right) \\
& d_{\mathrm{f} 2}=\left(\frac{\sigma_{22}}{Y_{\mathrm{T}}}\right)^{2}+\left(\frac{\sigma_{12}^{2}+\sigma_{23}^{2}}{S_{f}^{2}}\right)
\end{aligned}
$$

Constants $X_{\mathrm{T}}$ and $Y_{\mathrm{T}}$ are tensile strengths in the 1 and 2 directions, respectively, and for this material both have the same value; $S_{\mathrm{f}}$ is the through-thickness shear strength. When one of these two damage variables equals one, all the stress components that appear in the equation are set to zero.

Fig. 12 shows the stresses that participate in each failure mode.

For a smooth transition in the stresses in order to avoid sudden changes in the stiffness of the finite elements when damage occurs -and thus instability problems and lack of convergence during the simulation- the stress components were corrected using the following equation:

$\sigma_{i j}^{c o r}=\sigma_{i j} \cdot\left(1-\frac{2-e^{s\left(d_{i}-1 / 2\right)}}{2-e^{s / 2}}\right)$

where $\sigma_{i j} y \sigma_{i j}^{c o r}$ are the stress before and after the correction, $d_{i}$ is the damage parameter, and $s$ is the variable that controls the stiffness of the stress decay when the damage is

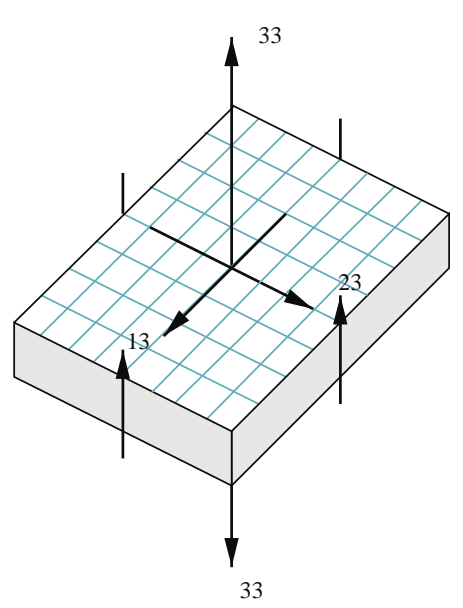

(a) Delamination

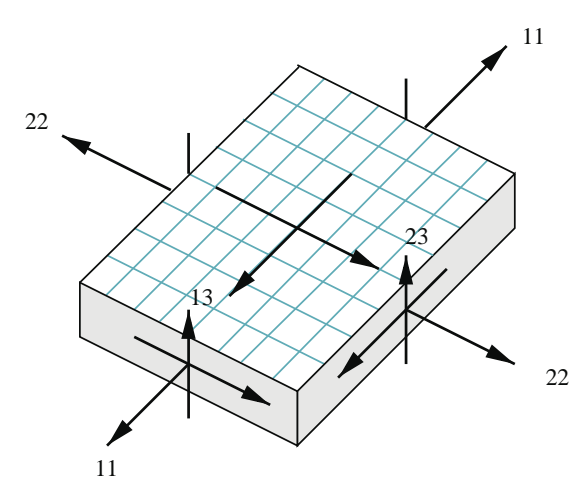

(b) Fiber failure

Fig. 12. Stress components that participates in each failure mode. 
Table 2

Material ply properties provided by the manufacturer and critical values of the strain for element deletion

\begin{tabular}{ll}
\hline Propery & Value \\
\hline Resin content $\%$ & 40 \\
$E_{1}(\mathrm{GPa})$ & 68.5 \\
$E_{2}(\mathrm{GPa})$ & 68.5 \\
$G_{12}(\mathrm{GPa})$ & 3.7 \\
$v_{12}$ & 0.11 \\
$X_{\mathrm{t}}(\mathrm{MPa})$ & 795 \\
$X_{\mathrm{c}}(\mathrm{MPa})$ & 860 \\
$Y_{\mathrm{t}}(\mathrm{MPa})$ & 795 \\
$Y_{\mathrm{c}}(\mathrm{MPa})$ & 860 \\
$S_{\mathrm{t}}(\mathrm{MPa})$ & 98 \\
$\varepsilon_{1 \mathrm{c}}$ & \\
$\varepsilon_{2 \mathrm{c}}$ & 0.02 \\
$\varepsilon_{3 \mathrm{c}}$ & 0.02 \\
\hline
\end{tabular}

close to 1. For the simulations, the value $s \quad 30$ was adopted.

The simulation of ballistic impacts, which commonly involves the perforation of the target, requires the use of a finite element erosion criterion. When damage occurs in a finite element, the stresses on it drops to zero and large deformations appear. A maximum strain criteria was adopted to remove the distorted elements: after each time increment the strains in the directions of the composite material (fibers $\varepsilon_{1}, \varepsilon_{2}$ and out-of plane $\varepsilon_{3}$ ) are calculated; if one of them reaches a critical value the element is removed. Table 2 shows these critical values.

The material model described herein was programmed in Fortran in a user subroutine to be implemented in the numerical code ABAQUS/Explicit.

\subsection{Finite element mesh}

For the numerical simulations, a three dimensional nonhomogenous mesh was used, with smaller elements in the centre of the laminate where the impact occurred. The sensitivity of the mesh was analysed with successive space discretizations. Finally the selected mesh had 116560 8-node brick elements with reduced integration (C3D8R in ABAQUS notation), with two elements per ply along the thickness. The projectile was modelled using 4-node shell elements with reduced integration (S4R in ABAQUS notation) since no plastic deformation was found during the real impact test; 150 elements comprised the sphere.

\subsection{Damage evaluation}

To measure the damaged area after impact in the numerical simulations, a Fortran code program was developed. This routine reads the eroded elements of the laminate and the displacement of the nodes; then calculates the reduction of the thickness at each material point, allowing the quantification of the damaged area. The zone was assumed to be damaged when the thickness was reduced by more than $10 \%$.

\section{Results}

\subsection{Model validation}

To validate the material model for the laminate composite, two variables are selected, residual velocity for normal impacts and damage extension for normal and $45^{\circ}$ oblique impacts. Fig. 13 shows the good correlation between exper-

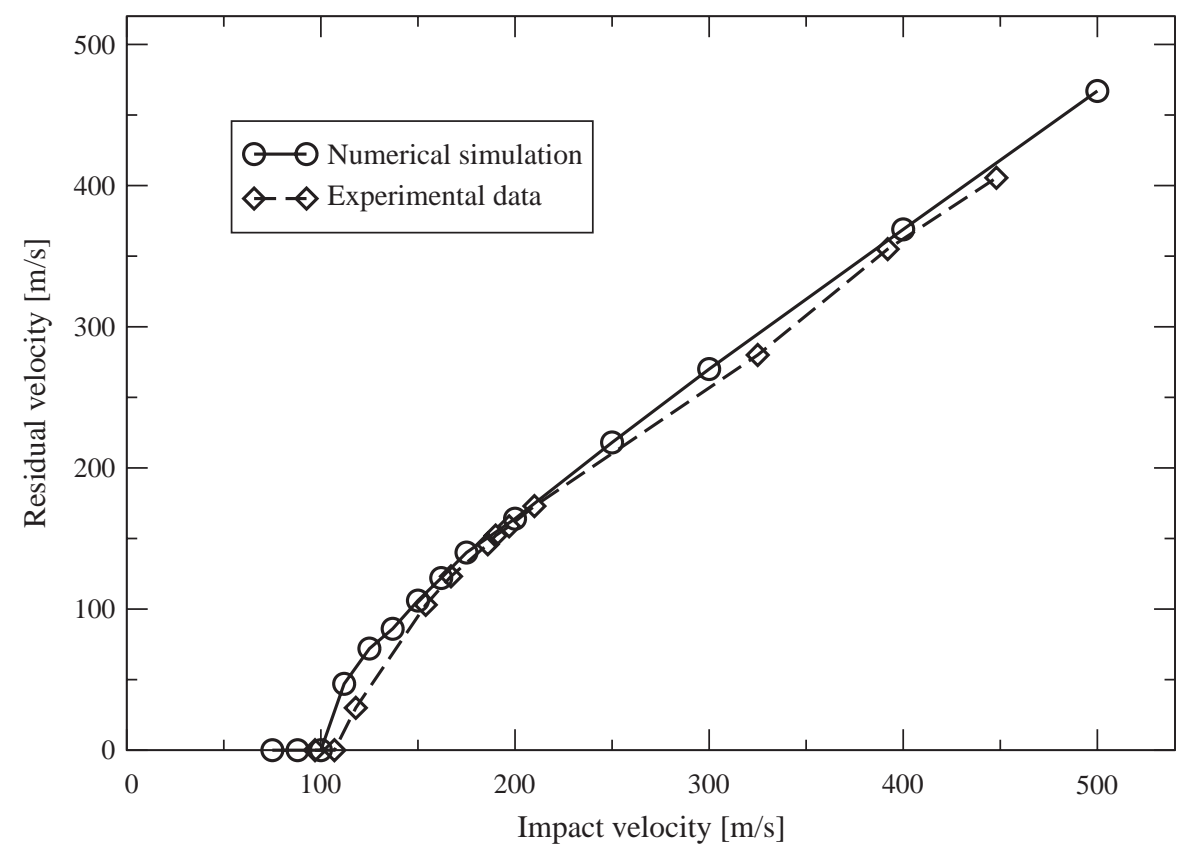

Fig. 13. Residual velocity for different normal impact velocities. Experimental and numerical results. 


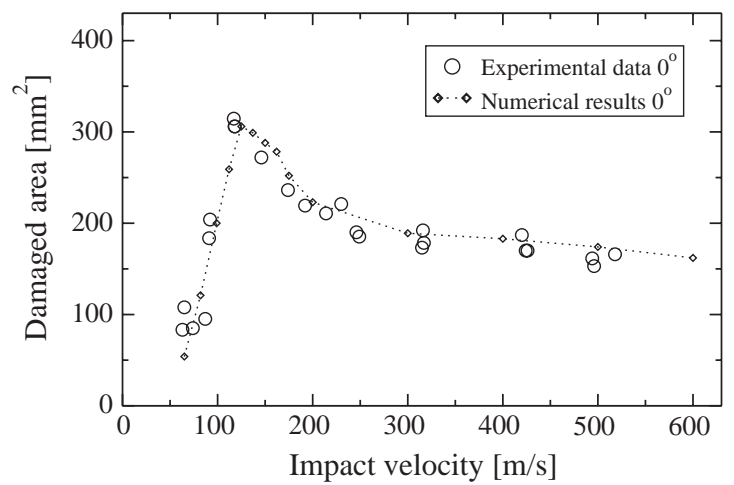

(a) $0^{\circ}$

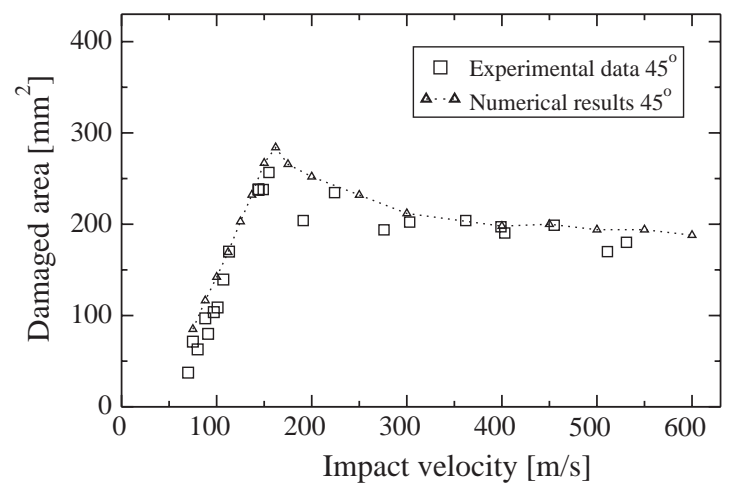

(b) $45^{\circ}$

Fig. 14. Damage area vs impact velocity for different impact angles. Experimental and numerical results.

imental test and numerical results for the residual velocity. At speeds close to the ballistic limit, small differences could be appreciated, but consistently lower than $5 \%$; as the impact velocity increased the error diminished.

The damage extent is also used to evaluate the reliability of the model. As shown in Fig. 14 for both impact angles, the model is able to estimate the damaged area, at a wide range of velocities below and above ballistic limit. Thus, the model estimated with adequate precision the two most important results of this problem, residual velocity and damaged area.

\subsection{Numerical simulations}

After the material model was demonstrated to be precise enough to estimate residual velocity and damage extent for high-velocity impact, the effect of impact velocity and impact obliquity was analysed in. For a broader data set, simulations at other impact angles $\left(30^{\circ}\right.$ and $\left.60^{\circ}\right)$ were undertaken. To explain the differences encountered, we need to take into account that some authors $[8,25]$ consider three different energy-absorption mechanisms:

- Laminate crushing: when the projectile impacts against the laminate, it breaks the material in front of it by compression, inducing the well-known plug-in process; its importance does not depend of the projectile's impact velocity.

- Linear momentum transfer: after a part of the laminate is detached the projectile accelerates it from the rest, at the projectile velocity. This mechanism increases in importance as the impact velocity increases.

- Fiber failure: This last failure mechanism appears only at low impact velocities, when the projectile speed is

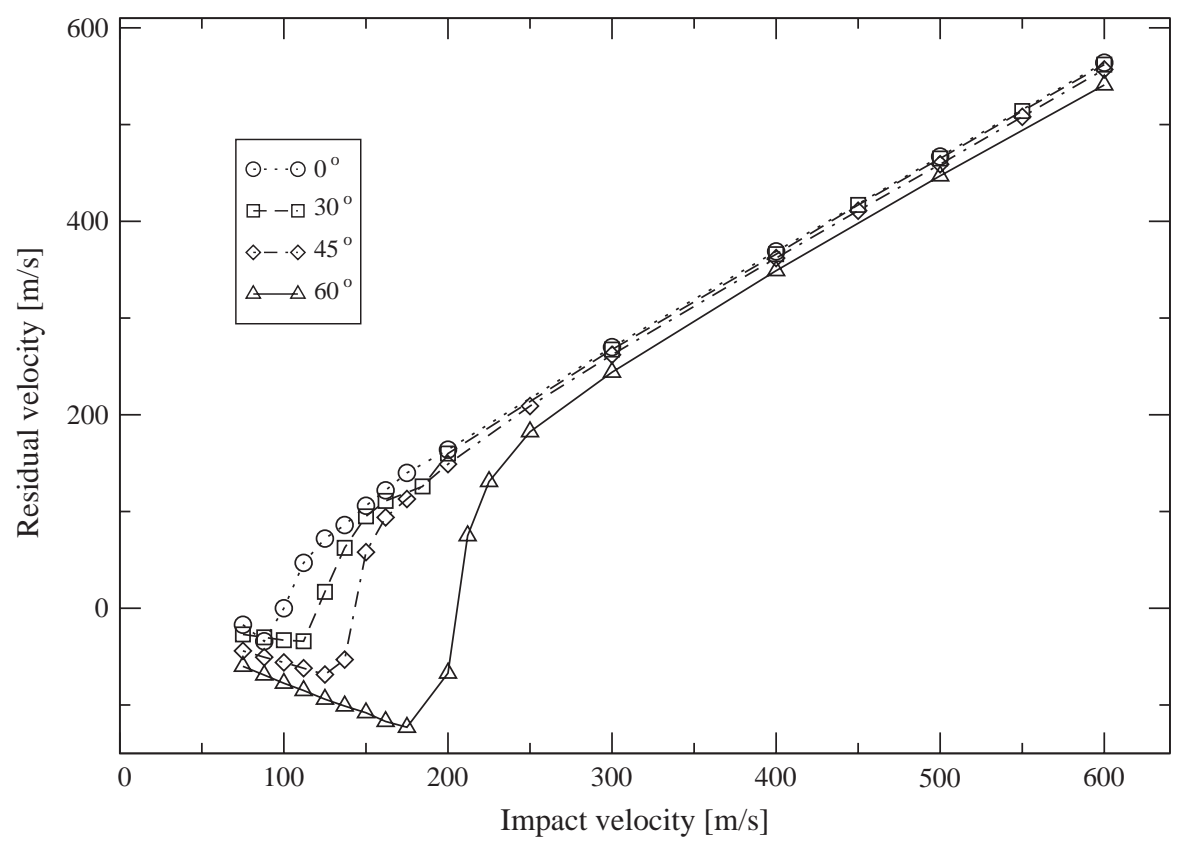

Fig. 15. Residual velocity vs. impact velocity for different impact angles. 
low enough to allow the wave propagation along the full thickness. This has less importance in the total absorbed energy.

First, the influence of impact velocity and obliquity on the residual velocity was analysed. Fig. 15 shows the relation between these three variables, including negative values of the residual velocity (rebound), positive values (perforation) and the limit between the two situations (ballistic limit).

At high impact velocities the differences in residual velocity are very small, less than $4 \%$. As stated above, in this range the main energy-absorbing mechanism is the linear momentum transfer, which depends on the mass of the laminate accelerated from rest to the projectile velocity; this mass is the same for any impact angle.

At velocities close to the ballistic limit, large differences are observed. In this case, a balance between kinetic energy of the projectile and work done by crushing of the laminate

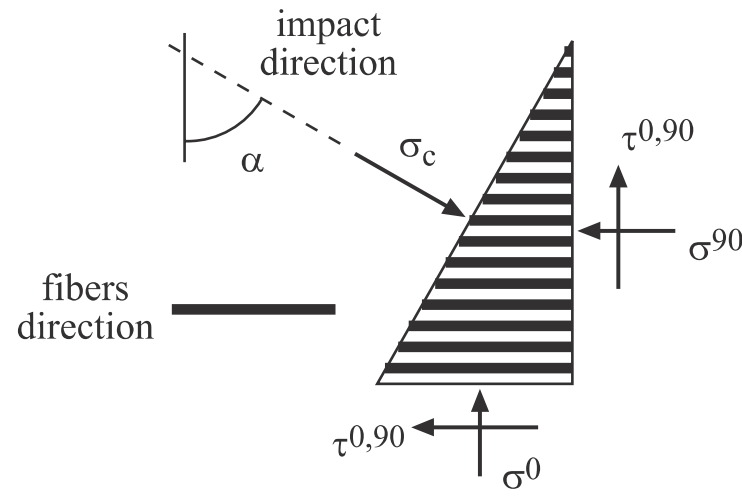

Fig. 16. Stresses in the laminate due to the crushing penetration mechanism of the projectile. could be achieved, since this is the main energy-dissipation mechanism at impact velocities close to $v_{\mathrm{bl}}$ [25].

$\frac{1}{2} m_{\mathrm{p}} v_{\mathrm{bl}}^{2}=\sigma_{\mathrm{c}}(\alpha) A_{\mathrm{p}} \frac{h}{\cos \alpha}$

$m_{\mathrm{p}}$ being the mass of the projectile, $A_{\mathrm{p}}$ the area of its cross section, $h$ the laminate thickness and $\sigma_{\mathrm{c}}$ a strength parameter of the composite that characterizes its resistance to crushing. This should depend on the direction of penetration, provided that the carbon fibers present a higher resistance to be flattened than does the matrix. This variation could be estimated using a basic quadratic damage criterion for the composite

$\left(\frac{\sigma^{0}}{\sigma_{\mathrm{c}}^{0}}\right)^{2}+\left(\frac{\sigma^{90}}{\sigma_{\mathrm{c}}^{90}}\right)^{2}+\left(\frac{\tau^{0,90}}{\tau_{\mathrm{c}}^{0,90}}\right)^{2}=1$

and assuming that penetration of the projectile into the woven laminate during crushing induces a nearly $1 \mathrm{D}$ compression stress state one (Fig. 16)

$\begin{aligned} \sigma^{0} & =\frac{\sigma_{\mathrm{c}}}{2}(1+\cos 2 \alpha) \\ \sigma^{90} & =\frac{\sigma_{\mathrm{c}}}{2}(1-\cos 2 \alpha) \\ \tau^{0,90} & =\frac{\sigma_{\mathrm{c}}}{2} \sin 2 \alpha\end{aligned}$

Table 3

Ratios of ballistic limits for different impact obliquities determined by numerical simulations and with Eq. (14)

\begin{tabular}{lll}
\hline & Numerical (Fig. 15) & Eq. (14) \\
\hline$v_{\mathrm{bl}}^{30} / v_{\mathrm{bl}}^{0}$ & 1.22 & 1.18 \\
$v_{\mathrm{bl}}^{45} / v_{\mathrm{bl}}^{0}$ & 1.45 & 1.46 \\
$v_{\mathrm{bl}}^{60} / v_{\mathrm{bl}}^{0}$ & 2.02 & 1.89 \\
\hline
\end{tabular}

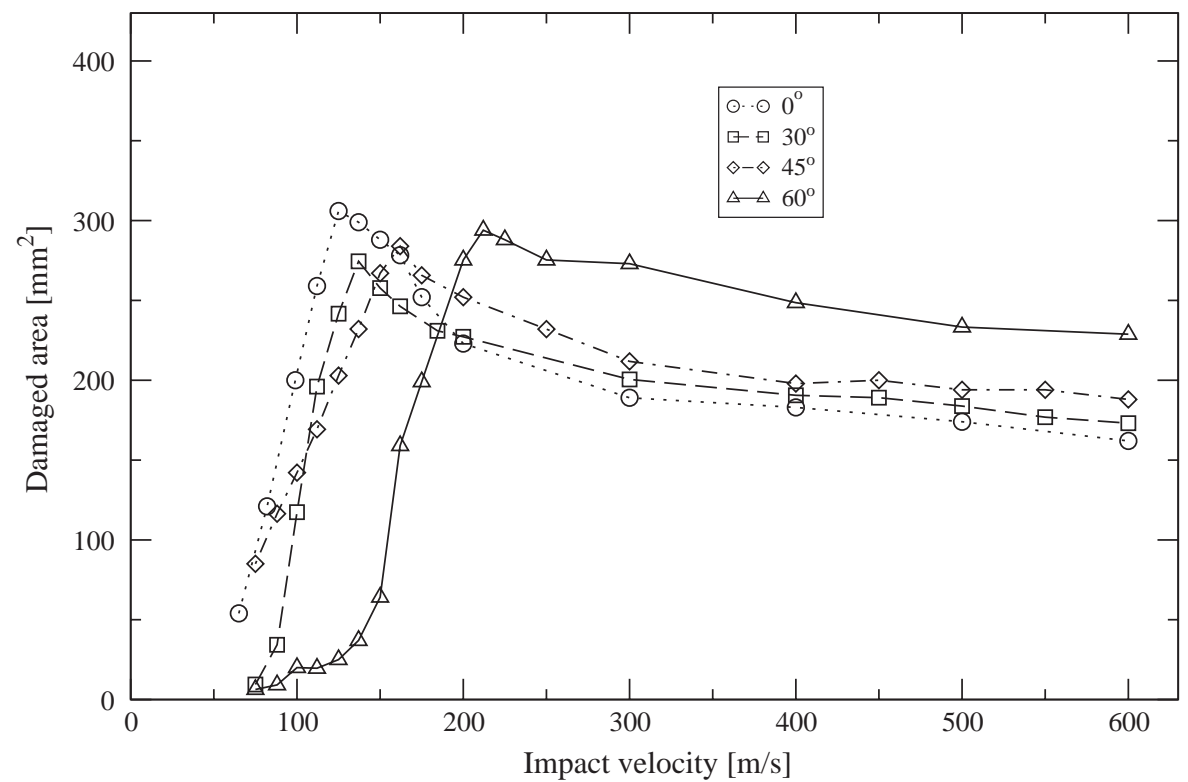

Fig. 17. Damaged area as function of impact velocity for different impact angles. 
In Eq. $10 \sigma^{0}, \sigma^{90}$ and $\tau^{0,90}$ are the stresses caused by the crushing process on the planes normal to directions $\alpha$ 0 and $\alpha 90$, and $\sigma_{\mathrm{c}}^{0}, \sigma_{\mathrm{c}}^{90}$ and $\tau_{\mathrm{c}}^{0,90}$ the corresponding strengths. Rearranging Eqs. (10) (13), $\sigma_{\mathrm{c}}$ could then be written as a function of $\alpha$. According to Eq. (9), the relation between the ballistic limits at two different angles $\alpha_{1}$ and $\alpha_{2}$ is given by

$\frac{v_{\mathrm{bl}}^{\alpha_{1}}}{v_{\mathrm{bl}}^{\alpha_{2}}}=\sqrt{\frac{\sigma_{\mathrm{c}}\left(\alpha_{1}\right)}{\sigma_{\mathrm{c}}\left(\alpha_{2}\right)}} \frac{\cos \alpha_{2}}{\cos \alpha_{1}}$

and taking a value for $\sigma_{\mathrm{c}}^{0}=60 \mathrm{MPa}$ (perpendicular to the plane crushing strength [25]), $\sigma_{\mathrm{c}}^{90}=160 \mathrm{MPa}$ (crushing of carbon/epoxy woven laminates in direction of fibers [35]) and $\tau_{\mathrm{c}}^{0,90}=70 \mathrm{MPa}$, the ratios of ballistic limits shown in Table 3 were calculated, which agree well with the values determined by numerical simulation.

The damaged area versus the impact velocity for different impact angles is plotted in Fig. 17. For impact velocities below ballistic limit, damage increased with the impact velocity, as observed experimentally. Since the component of the velocity normal to the laminate decreases as obliquity increases, and these types of materials are particularly sensitive to out-of-plane impacts, a reduction of damage extent is also observed as $\alpha$ rises. At high velocities, when penetration takes place, higher impact angles induce a larger damaged area due to the larger trajectory of the projectile through the laminate. In all cases the damaged surface diminishes as the impact velocity increases.

\section{Conclusions}

In this work, high-velocity impact tests were performed on thin woven carbon/epoxy laminates. The projectile, a steel sphere weighting $1.73 \mathrm{~g}$, was launched at a velocities ranging from 70 to $531 \mathrm{~m} / \mathrm{s}$ and at normal as well as oblique $\left(45^{\circ}\right)$ incidence. The residual velocity was measured with a high-speed digital camera and the ballistic limit was also determined. The specimens were then inspected with C-Scan and were afterwards cut with a diamond yarn to determine both the damage extent and morphology.

A number of impact tests were simulated with a finite element model for a larger range of impact velocities and obliquities (including the experimental tests). The damage on the CFRP material was modelled with a damage criterion based on that due to Chang Chang [32] and modified for a woven laminate. The finite element model was validated with experimental results in a wide range of velocities and at two different angles $\left(0^{\circ}\right.$ and $\left.45^{\circ}\right)$ considering both residual velocity and damage extent. It was considered that these experimental results were adequate to calibrate the numerical model.

Fundamental physical and geometrical relationships also enabled analyses of the results provided by the experimental and numerical tests. From these results presented and discussed, the main conclusions are as follows:
- Below ballistic limit, the damage extent increases with the projectile initial velocity both for normal and oblique impacts. Above the ballistic limit the damage extent decreases with impact velocity.

- The maximum damage inflicted, corresponding to the ballistic limit, was produced at normal incidence, as a consequence of the characteristic rhomboidal failure shape in the laminate when impact takes place without obliquity.

- Below the ballistic limit, the damage extent for normal impact is larger than that for the oblique impact. The damage extent at higher velocities appears to be greater for oblique impacts. This switch is related to the change in the damage mechanism: delamination below $v_{\mathrm{bl}}$ (extension proportional to the normal component of the projectile velocity) and piercing above $v_{\mathrm{bl}}$ (damage extent proportional to the projection of the projectile trajectory against the laminate).

- The ballistic limit increases with impact obliquity as the fibers present a higher resistance to be flatten than the matrix. Well above the ballistic limit, the residual velocity is not affected by the impact obliquity since the main energy absorbing mechanism is the linear momentum transfer.

\section{Acknowledgement}

The authors are indebted to the Comisión Interministerial de Ciencia y Tecnología of Spain for the financial support of this work (Project MAT98-0273).

\section{References}

[1] Airoldi A, Cacchione B. Modelling of impact forces and pressures in lagrangian bird strike analyses. Int J Impact Eng 2006;32: 165177.

[2] Anghileri M, Castelleti LML, Invernizzi F, Mascheroni M. A survey of numerical models for hail impact analysis using explicit finite element codes. Int J Impact Eng 2005;31:929 44.

[3] Mines RAW, McKown S, Birch RS. Impact of aircraft rubber tyre fragments on aluminium alloy plates: I experimental. Int J Impact Eng 2007;34(4):627 46.

[4] Hai jun X, Rong ren W. Aeroengine turbine blade containment tests using hig speed rotor spin test facility. Aerospace Sci Technol 2006;10:501 8.

[5] Schonberg WP. Hole size and crack length models for spacecrafts walls under oblique hypervelocity projectile impact. Aerospace Sci Technol 1999;3:461 71.

[6] Farenthold EP, Hernandez RJ. Simulation of orbital debris impact on the space shuttle wing leading edge. Int J Impact Eng 2006; 33(1 12):231 43 .

[7] Columbia Accident Investigation Board, Report of Columbia acci dent investigation board, Tech. rep., US National Aeronautics and Space Administration (August 2003).

[8] Cantwell WJ, Morton J. Comparison of low and high velocity impact response of CFRP. Composites 1989;20(6):545 51.

[9] Bland PW, Dear JP. Observations on the impact behaviour of carbon fibre reinforced polymers for the qualitative validation of models. Compos Part A Appl Sci Manuf 2001;32:1217 27. 
[10] Caprino G, Lopresto V, Santoro D. Ballistic impact behaviour of stitched graphite/epoxy laminates. Compos Sci Technol 2007;67(3 4): 32535 .

[11] Reid SR, Wen HM. Impact behaviour of fibre reinforced composite materials and structures. Cambridge: Woodhead Publication; 2000, Ch Perforation of FRP laminates and sandwich panels subjected to missile impact.

[12] Cantwell WJ, Morton J. Impact perforation of carbon fibre reinforced plastic. Compos Sci Technol 1990;38:119 41.

[13] Sun CT, Potti V. A simple model to predict residual velocities of thick composite laminates subjected to high velocity impact. Int J Impact Eng 1996;18(3):339 53.

[14] Hammond RI, Proud WG, Goldrein HT, Field JE. High resolution optical study of the impact of carbon fibre reinforcedpolymers with different lay ups. Int J Impact Eng 2004;30:69 86.

[15] Herzsberg I, Weller T. Impact damage resistance of buckled carbon/ epoxy panels. Compos Struct 2006;73:130 7.

[16] Hosur MV, Vaidya UK, Ulven C, Jeelani S. Performance of stitched/ unstitched woven carbon/epoxy composites under high velocity impact loading. Compos Struct 2004;64:455 66 .

[17] Larsson F. Damage tolerance of a stitched carbon/epoxy laminate. Compos Part A: Appl Sci Manuf 1997;28(11):923 34.

[18] Tanabe Y, Aoki M, Fujii K, Kasano H, Yasuda E. Fracture behavior of cfrps impacted by relatively high velocity steel sphere. Int J Impact Eng 2003;28:627 42.

[19] Tanabe Y, Aoki M. Stress and strain measurements in carbon related materials impacted by a high velocity steel sphere. Int J Impact Eng 2003:28:1045 59.

[20] Will MA, Franz T, Nurick GN. The effect of laminate stacking sequence of CFRP filament wound tubes subjected to projectile impact. Compos Struct 2002;58:259 70.

[21] López Puente J, Zaera R, Navarro C. The effect of low temperatures on the intermediate and high velocity impact response of CFRP. Compos Part B 2002;33:559 66.

[22] Kim H, Welch DA, Kedward KT. Experimental investigation of high velocity ice impacts on woven carbon/epoxy composite panels. Compos Part A Appl Sci Manuf 2003;34:25 41
[23] Abrate S. Impact on laminated composite materials. Appl Mech Rev 1991;44:155 90.

[24] Abrate S. Impact on laminated composite materials: recent advances. Appl Mech Rev 1994;47:517 44.

[25] López Puente J, Zaera R, Navarro C. An analytical model for high velocity impacts on thin cfrps woven laminates. Int J Solids Struct 2007; 44:2837 51.

[26] Chen JK, Allahdadi FA, Carney TC. High velocity impact of graphite/epoxy composite laminates. Compos Sci Technol 1997;57:1369 79.

[27] López Puente J, Zaera R, Navarro C. Numerical modelling of high velocity impact on CFRPs at low temperature. In: 14th Dymat Technical Meeting, Sevilla Spain 2002; p. 1219.

[28] Lamontagne CG, Manuelpillai GN, Taylor EA, Tennyson RC. Normal and oblique hypervelocity impacts on carbon fiber compos ites. Int J Impact Eng 1999;23:519 32.

[29] Lamontagne CG, Manuelpillai GN, Kerr JH, Taylor EA, Tennyson RC, Burchell MJ. Projectiles density, impact angle and energy effects on hypervelocity impact damage to carbon fiber/peek composites. Int J Impact Eng 2001;26:381 98.

[30] López Puente J, Zaera R, Navarro C. High energy impact on woven laminates. J de Physique IV 2003;110:639 44.

[31] Abaqus Explicit User's Manual, version 6.5 Edition, HKS, 2005.

[32] Chang F, Chang KA. A progressive damage model for laminated composites containing stress concentrations. J Compos Mater 1987;21:834 55.

[33] Hou JP, Petrinic N, Ruiz C, Hallet SR. Prediction of impact damage in composite plates. Compos Sci Technol 2000;60:273 81 .

[34] Iannucci L, Willows M. An energy based damage mechanics approach to modelling impact onto woven composite materials part I: Numerical models. Compos Part A: Appl Sci Manuf A 2003;37(11):2041 56.

[35] Mamalis AG, Manolakos DE, Ioannidis MB, Papapostolou DP. On the response of thin walled cfrp composite tubular components subjected to static and dynamic axial compressive loading: experi mental. Compos Struct 2005;69(4):407 20. 